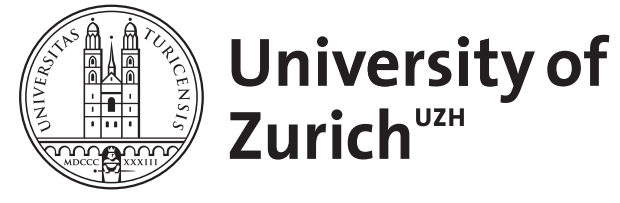
Archive

University of Zurich

University Library

Strickhofstrasse 39

CH-8057 Zurich

www.zora.uzh.ch

Year: 2021

\title{
Unusual colonic polyp in a young woman
}

Bertolini, Reto ; Bode, Peter K ; Sawatzki, Mikael

DOI: https://doi.org/10.1053/j.gastro.2020.06.052

Posted at the Zurich Open Repository and Archive, University of Zurich

ZORA URL: https://doi.org/10.5167/uzh-188787

Journal Article

Accepted Version

Originally published at:

Bertolini, Reto; Bode, Peter K; Sawatzki, Mikael (2021). Unusual colonic polyp in a young woman. Gastroenterology, 160(3):e12-e13.

DOI: https://doi.org/10.1053/j.gastro.2020.06.052 


\section{Journal Pre-proof}

Unusual colonic polyp in a young woman

Reto Bertolini, Peter K. Bode, Mikael Sawatzki

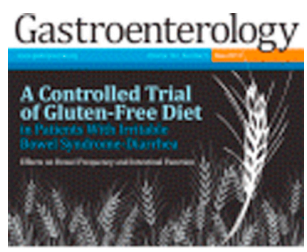

$\begin{array}{ll}\text { PII: } & \text { S0016-5085(20)34856-3 } \\ \text { DOI: } & \text { https://doi.org/10.1053/j.gastro.2020.06.052 } \\ \text { Reference: } & \text { YGAST 63592 }\end{array}$

To appear in: Gastroenterology

Accepted Date: 23 June 2020

Please cite this article as: Bertolini R, Bode PK, Sawatzki M, Unusual colonic polyp in a young woman, Gastroenterology (2020), doi: https://doi.org/10.1053/j.gastro.2020.06.052.

This is a PDF file of an article that has undergone enhancements after acceptance, such as the addition of a cover page and metadata, and formatting for readability, but it is not yet the definitive version of record. This version will undergo additional copyediting, typesetting and review before it is published in its final form, but we are providing this version to give early visibility of the article. Please note that, during the production process, errors may be discovered which could affect the content, and all legal disclaimers that apply to the journal pertain.

(C) 2020 by the AGA Institute 


\section{Title page:}

Title: Unusual colonic polyp in a young woman

Authors: Reto Bertolini ${ }^{1}$, Peter K. Bode ${ }^{2}$, Mikael Sawatzki ${ }^{1}$.

1 Department of Gastroenterology and Hepatology, Kantonsspital, St. Gallen, Switzerland

2 Institute of Pathology, University Hospital, Zürich, Switzerland

\section{Correspondence:}

Reto Bertolini, MD

Department of Gastroenterology and Hepatology

Kantonsspital St. Gallen

Rorschacherstrasse 95

$\mathrm{CH}-9007$ St. Gallen, Switzerland

Phone: +41714941474

e-mail: reto.bertolini@kssg.ch

Keywords: colon, polyp, NTRK-rearranged spindle cell neoplasm, sarcoma

Word count: Question 158, Answer 325

Contributors: BR wrote the original draft of this article. BR and SM provided the polypectomy/histology with enclosed images. BPK worte and reviewed the pathohistological section. All authors contributed to the final edit of the piece.

Funding: The authors have not declared a specific grant for this research from any funding agency in the public, commercial or not-for-profit sectors.

Competing interests: None declared. 


\section{Manuscript}

\section{Unusual colonic polyp in a young woman \\ Question}

A 25-year-old Eritrean woman was admitted with a four week history of abdominal pain and weight loss of $10 \mathrm{~kg}$ without diarrhoea and without family history of neoplasia. Physical examination was significant for mild tenderness over the right abdomen. Hemoglobin was decreased with $96 \mathrm{~g} / \mathrm{l}$ (normal 120-160 $\mathrm{g} / \mathrm{l})$ and CRP elevated with $114 \mathrm{mg} / \mathrm{l}(\mathrm{n}<8 \mathrm{mg} / \mathrm{l})$ with normal white cell count. Contrast-enhanced CT of the chest and abdomen showed a polypoid hyperdense intraluminal mass measuring $25 \mathrm{~mm}$ in the ascending colon (Fig. A) without metastases. Colonoscopy revealed a pedunculated polyp with a head size of $25 \mathrm{~mm}$ with ulcerated surface and a stalk size of $10 \mathrm{~mm}$ in the ascending colon (Fig. B). The polyp was lifted after submucosal injection into the stalk with 1:100'000 adrenaline, saline, indigocarmine and succinylated gelatine (Fig. C). Hot snare (25mm snare) polypectomy and bleeding prevention with clips were successfully performed with retrieval of the polyp for histopathological examination (Fig. D, E).

\section{What is the diagnosis?}




\section{Answer}

Journal Pre-proof

Histology revealed an unencapsulated tumor consisting of ovoid spindle cells with eosinophilic cytoplasm arranged in a loose fascicular growth pattern set in a collagenous background with a mild lymphocytic inflammatory component. The mitotic count was up to 4/10 HPF, without tumour necrosis and no high grade cytological atypia (Fig F, G). Immunohistochemistry showed the tumour cells to be diffusely and strongly positive for S100 (Fig. H) and CD34 (Fig. I) whereas DOG1, CD117, desmin, alpha SMA, caldesmon, MelanA, HMB-45 amongst others were negative. Molecular analysis detected a NTRK1 (neurothrophic receptor tyrosine kinase) -TPM3 gene fusion by new genome sequencing (using Oncomine Focus Assay, Thermo Fisher).

This case is the first report of a novel group of NTRK-rearranged spindle cell neoplasms in the colon, defined by S100 / CD34 co-expression and a NTRK1-TPM3 gene fusion. Suurmeijer et al. (1) reported this heterogeneous entity with at most low malignant potential in soft tissue tumors. In this case series (1) only one tumor was detected in the gastrointestinal tract (stomach). Wong et al (2) also reports different locations like soft tissue, liver, uterus or lung with various outcome of NTRK-rearranged spindle cell neoplasms. The proto-oncogenes NTRK encode the TRK (tropomyosin receptor kinases) proteins and specific and highly effective TRK inhibitors targeted therapies for adults and children exist (3).

This case was presented at our interdisciplinary tumor-board with the recommendation of oncological resection. Laparoscopic right hemicolectomy with complete mesocolic excision was performed without any signs of peritoneal seeding or other abnormalities. No residual tumor could be detected after hemicolectomy.

No data are available regarding prognosis and management of this tumor entity. Because of low mitotic rate (4 mitosis per $10 \mathrm{HPF}$ ) without metastases, this tumor was classified as low grade in our interdisciplinary sarcoma board. According to the surveillance of low grade sarcoma of the soft tissue, surveillance with CT (every 6 months for two years and yearly for 5 years) and yearly colonoscopy (for 5 years) were recommended. 


\section{References}

1. Suurmeijer AJH et al. Genes Chromosomes Cancer 2018; 57: 611-621

2. Wong DD et al. Pathology 2020; 52: 401-409

3. Drilon A et al. New England Journal of Medicine 2018; 22: 731-739 


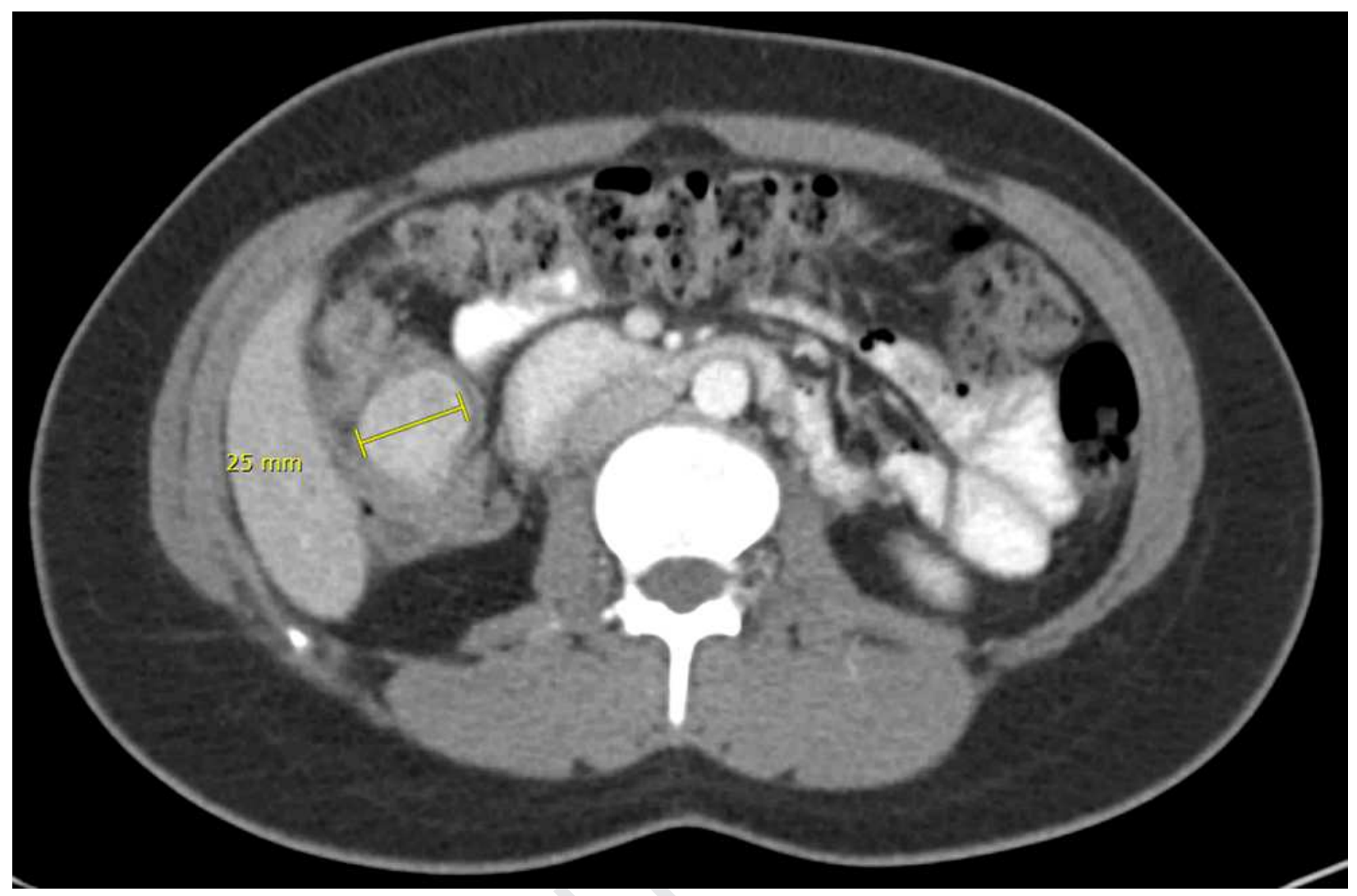




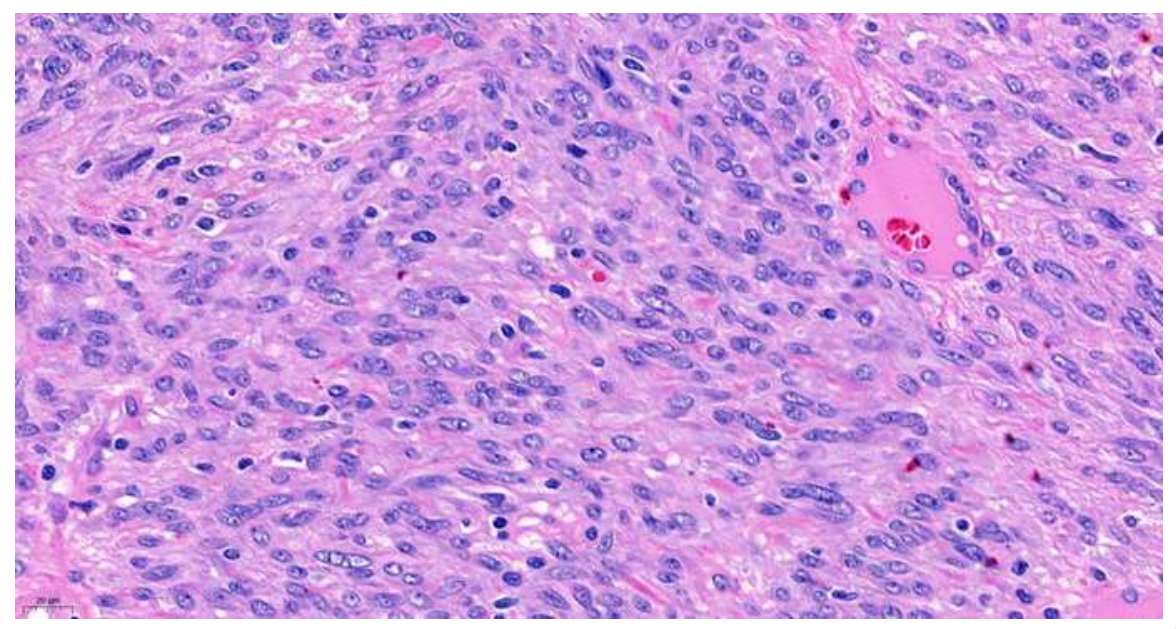




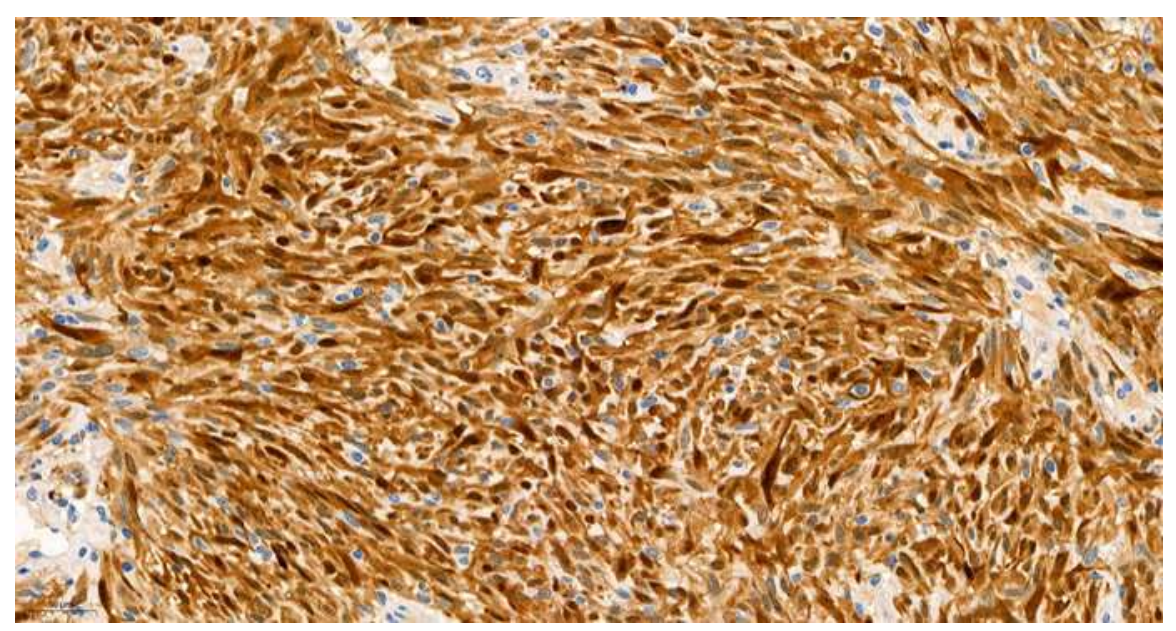




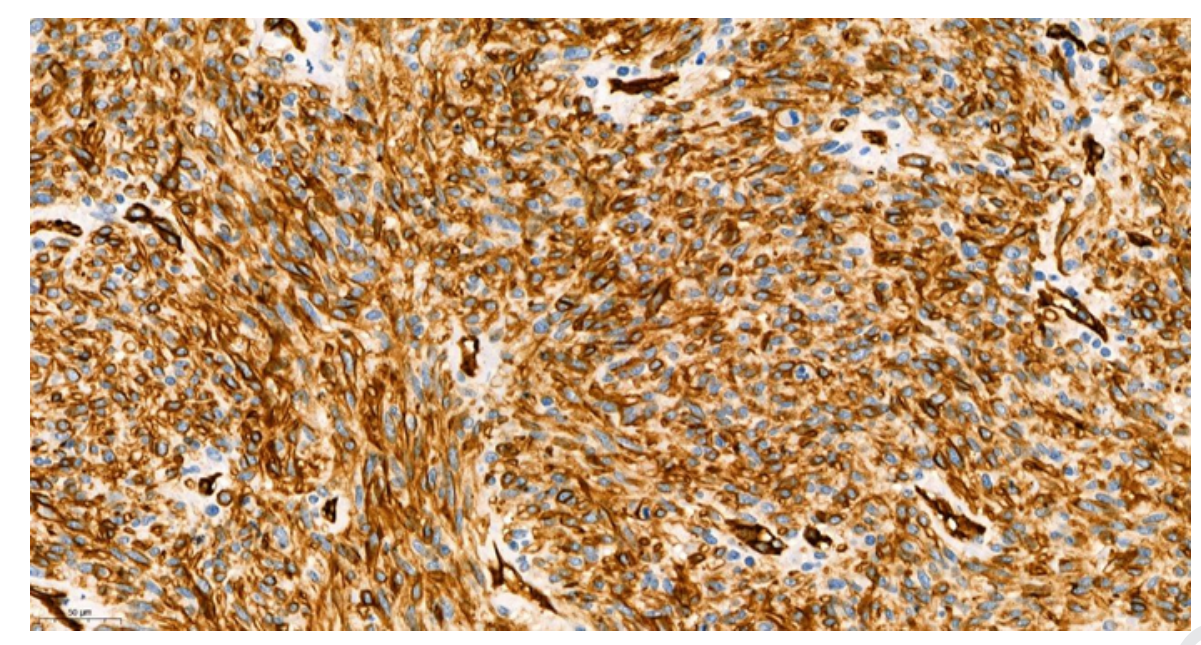




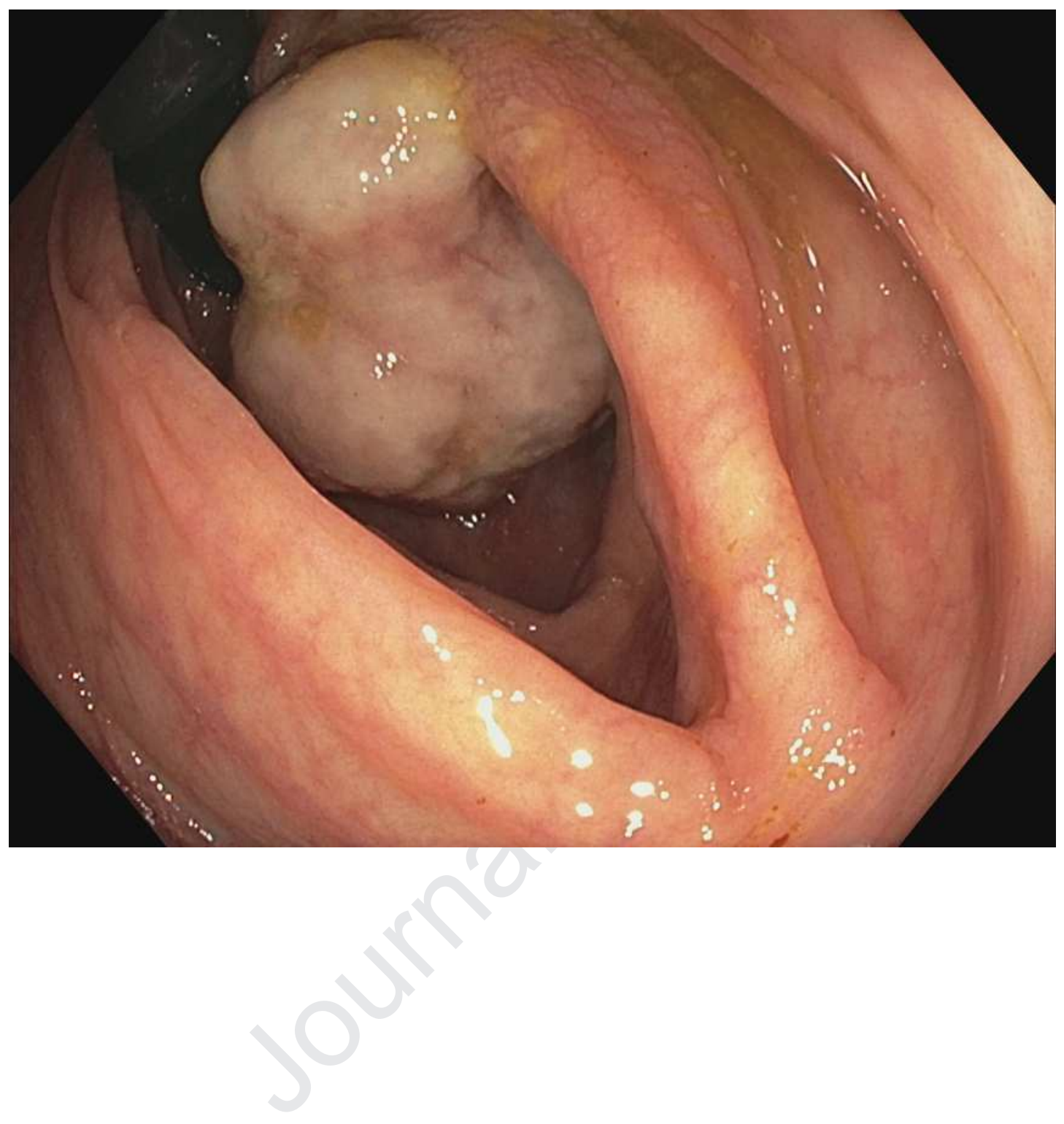




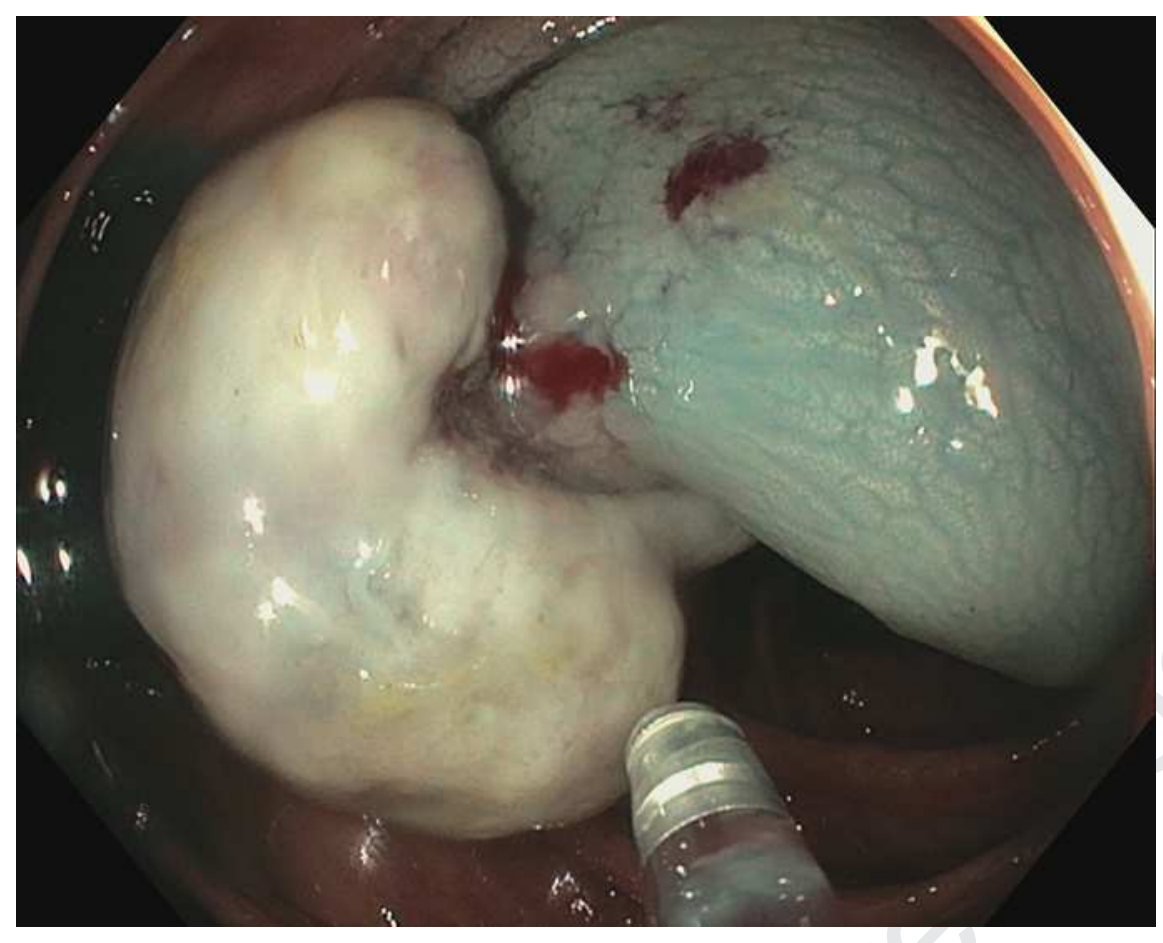




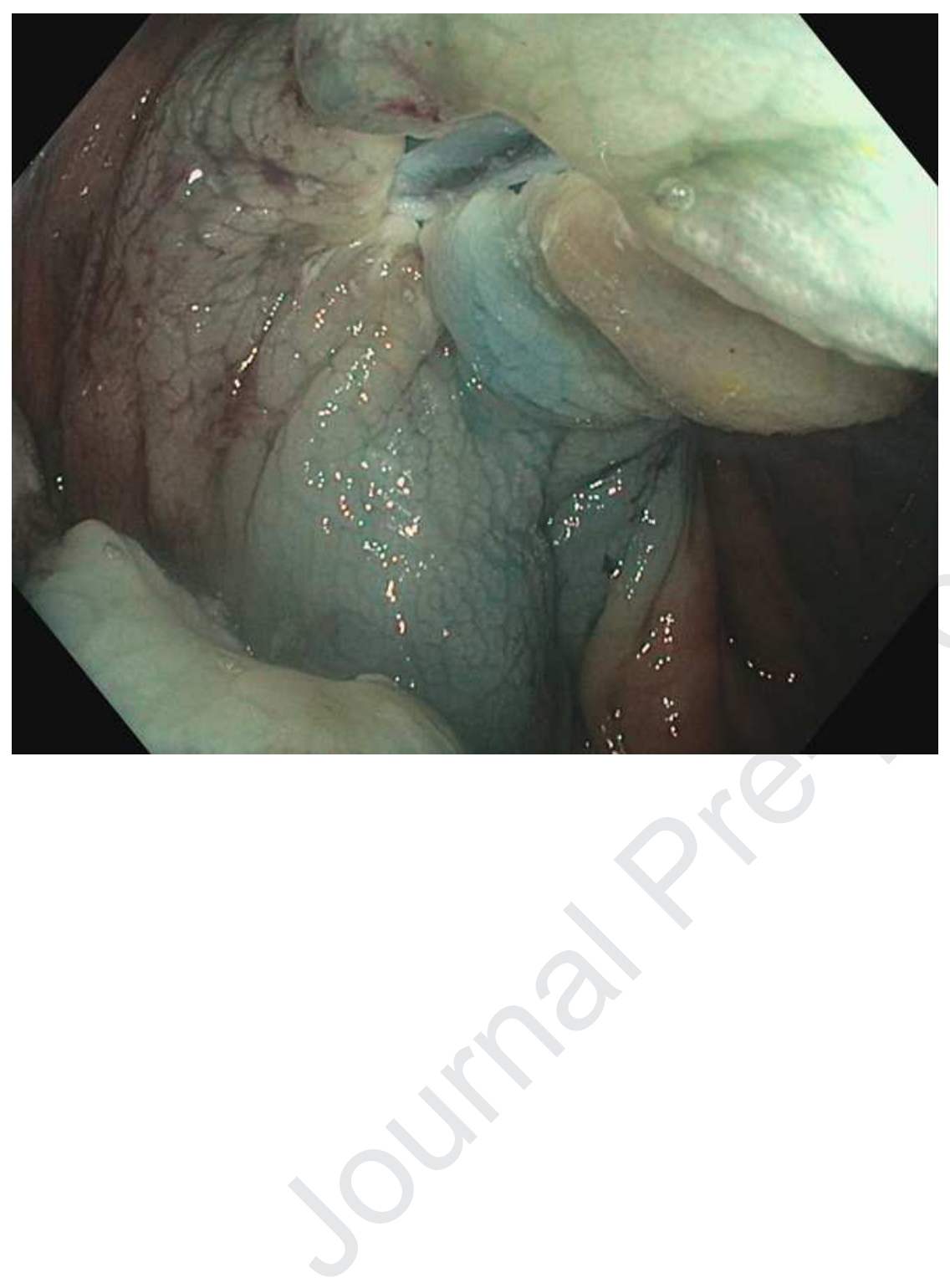




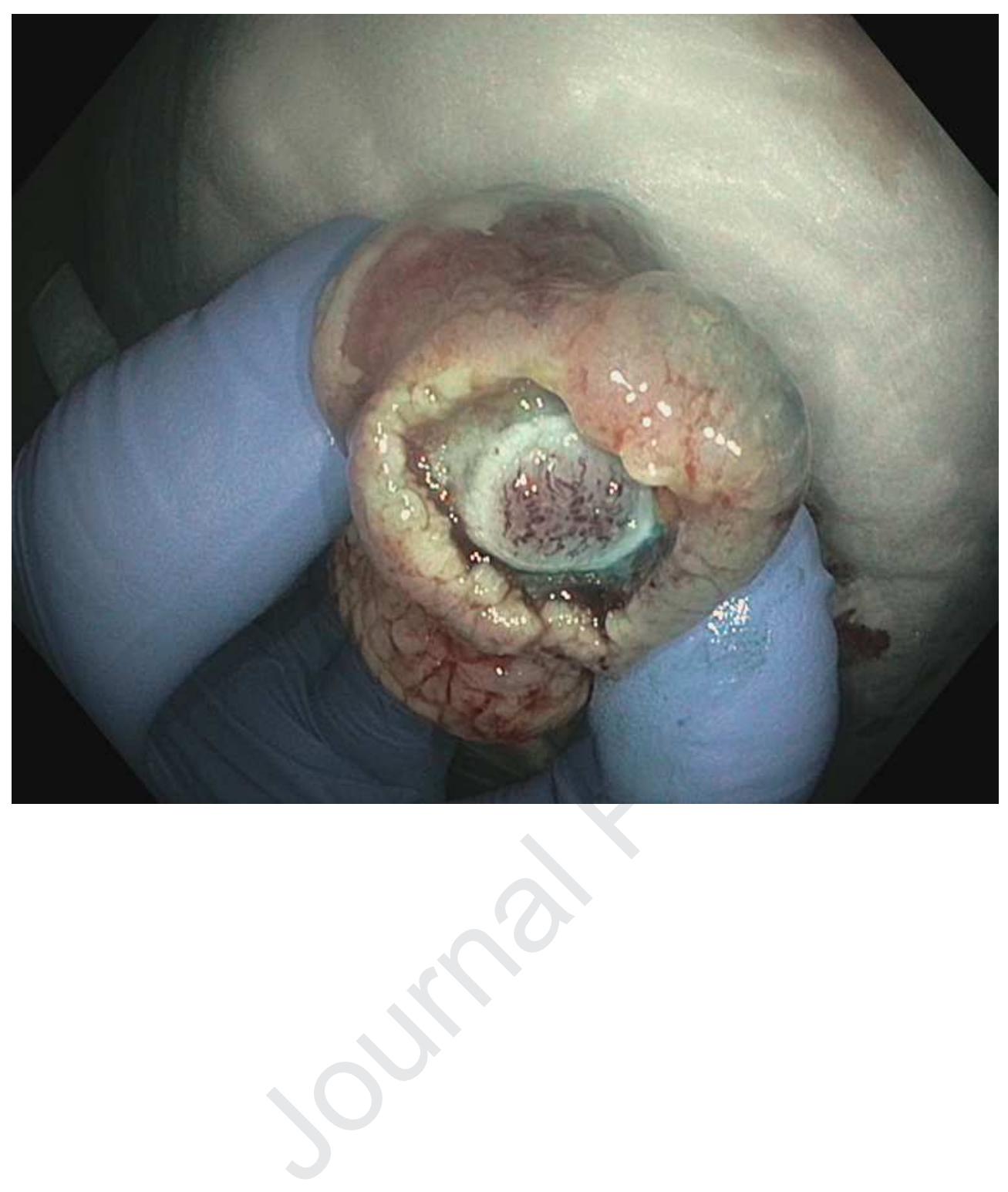




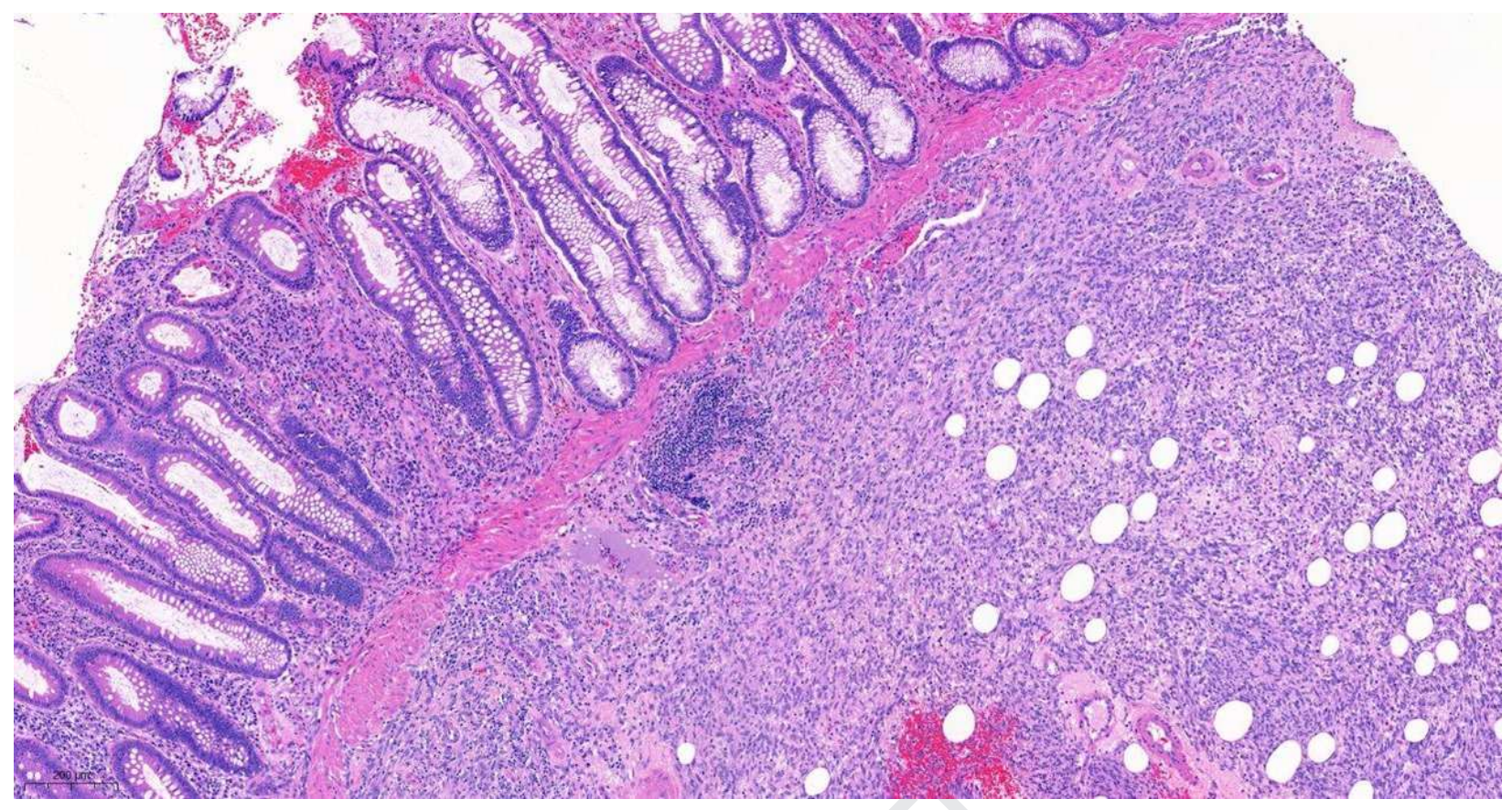

